\title{
Promoting Students' Understanding of the Concept of Pressure: Active Learning Environment versus Traditional One
}

\author{
Güner Tural \\ Department of Mathematics and Science Education, Ondokuz Mayıs University, Samsun, Turkey \\ $\bowtie$ guner.tural@omu.edu.tr
}

\begin{abstract}
One of the topics students have understanding difficulties in science is pressure. The study investigates the effectiveness of an active-learning environment on the students' understanding of the concept of pressure. The sample consisted of 30 students from a public secondary school in Turkey. This study used a pre-test, post-test, quasi-experimental research design with a control group. Ten lessons were conducted with both groups. The control group was taught using the coursebook's two activities, while the experimental group was taught using additional activities and models. After the treatment, a post-test was given to both groups to determine the active-learning environment's effectiveness on the students' understanding of the concept of pressure. Interviews were also conducted with the experimental group. The post-test results showed a significant difference in favor of the experimental group. It was determined that students in both groups had misunderstandings of the topic before and after instruction. The interviews showed that the experimental group students perceive that the active learning environment facilitated better and easier learning. The conclusion that can be drawn is that the active learning environment was more effective for the students in the experimental group to learn about the concept of pressure.
\end{abstract}

Keywords: active learning, hands-on activity, model, pressure, understanding.

How to Cite: Tural, G. (2020). Promoting Students' Understanding of the Concept of Pressure: Active Learning Environment versus Traditional One. Mimbar Sekolah Dasar, 7(3), 284-303. doi:https://doi.org/10.17509/mimbar-sd.v7i3.29391.

INTRODUCTION The changing needs of the individual and society necessitate the development of individuals who can produce and use information, solve problems, and communicate effectively. As science is pervasive, science education is one of the most critical subjects in school. Science educators desire meaningful and relevant science learning for their students. However, learners encounter difficulties due to the abstract nature of many science concepts such as pressure, including the subtopics of pressure in solids, pressure in liquids, and gas pressure. A plethora of literature explains the study of all the subtopics of pressure (e.g., Besson 2010; Besson and Viennot 2004; Engel Clough and Driver 1985; Kariotoglou and Psillos 1993; Psillos and Kaiotoglou 1999; Sere 1982; She 2005; Şahin et al. 2012; Taylor and Lucas 2000; Tytler 1992; Tytler 1998). These studies confirm that students have difficulty learning pressure-related concepts because it is abstract, like many science topics. Although these studies have indicated that students have difficulty understanding' pressure,' there are limited studies showing ways to overcome these difficulties. Hence, in this context, science learning environments need to be examined. 
Güner Tural, Promoting Students' Understanding of the Concept of Pressure: Active Learning...

Traditional learning environments often use the lecture method placing teachers in the center and students as passive listeners in the learning process. Such a learning environment emphasizes content rather than process. While this method may sometimes be useful to transfer a lot of content to many learners, desired learning outcomes may not be achieved since students generally memorize the information and acquire surface knowledge in this traditional learning environment. In contrast, in an active-learning environment, students become active participants in the learning process, and teachers act as a guide to promote student learning by encouraging them to participate actively. Moreover, active learning does not consist only of active work; it also includes cognitive and social dimensions (Watkins et al. 2007).

A plethora of research has been carried out on the effects of active learning on student progress. In a study carried out by Acar Sesen and Tarhan (2011), an experimental group of high school students received active learning implementation on the "acids and bases" topic. The study reported that active-learning instruction encouraged better scientific conceptions and fewer misconceptions than teacher-centered teaching. In addition to the students' performance, their perceptions of effective science learning also provide us important information. Owen et al. (2008) examined students' perceptions of the different learning activities within their physics lessons. They reported that the first three activities with the highest mean score were experimenting, working in a group, and making things. In contrast, the text-based exercises were unpopular and were less effective for students learning.

The research reports above suggest that lessons on pressure can be made more concrete and understandable in an active learning environment where students observe and practice. The present study investigates the effectiveness of an active-learning climate on the students' understanding of pressure.

\section{LITERATURE REVIEW}

\section{Active Learning and Related Studies}

Nowadays, students are seen as active learners instead of passive recipients (Fernandez, 2017). Learner-centered pedagogy requires students to have an active role in the process of knowledge acquisition. Active learning includes a variety of specific learner-centered instructional strategies to teach science. For instance, students are required to do hands-on, inquiry-oriented activities, and analyze problem-oriented scenarios (Taraban et al. 2007). The theoretical roots of active learning can be traced back to Jerome Bruner's work, which has served as an essential basis for constructivism, stressing learners' active role in learning and constructing their knowledge base (Niemi et al., 2016). There are three distinctive characters of differences between constructivist instruction and conventional instructions. Firstly, constructivist instruction construct knowledge actively rather than knowledge acquisition. 
Secondly, It defines teaching as supporting the student's constructive processing of understanding rather than delivering information. Lastly, teaching in constructivism is a learning-teaching concept rather than a teaching-learning concept. Hence, learners, not teaching, are the center of learning in constructivist instruction (Kim 2005). Bonwell and Eison (1991) explained strategies that support active learning as "instructional activities involving students in doing things and thinking about what they are doing." They suggest that active learning requires students not only to listen but also to write, read, discuss, and engage in solving problems.

Studies from various disciplines show that active learning strategies to learn environments affect students' learning effectiveness, academic achievement, attitude, critical thinking, and motivation. For example, Chiu and Cheng (2017) investigated the effects of active learning classrooms on student perceptions of their learning experience and the relationship with academic performance. The results showed that active learning classrooms encourage more creativity and innovation than the regular classroom. Killian and Bastas (2015) examined students' attitudes toward sociology and their performances in active-learning environments using Team-Based Learning (TBL). The results showed that TBL classes have much more positive attitudes toward the discipline than lecture-based learning classes. Fernandez (2017) compared inquiry-based learning and traditional instruction on the learning of thermal physics concepts. The inquiry-based learning group demonstrated significant gains in conceptual understanding and student self-efficacy. Julia and Antoli (2018) analyzed 6th and 7th-grade students' motivation in long-term STEM-based active learning courses. The course included authentic learning activities based on real-world problems and introduced science, technology, and engineering concepts. The conclusion was that the STEM course motivated most of the students. Lastly, Kim et al. (2013) examined active learning modules on students' critical thinking in an undergraduate general science course. The results showed that active learning strategies promote student critical thinking.

The above literature indicates that active learning environments play an important role in many fields, such as science, sociology, physics, and engineering. Thus, an active learning environment was selected to examine students' understanding of the concept of pressure.

\section{Studies on Comparisons of Traditional and Nontraditional Learning Environments}

Lorsbach and Tobin (1995, p.20) state that "a learning environment is a construction of the individuals in a given social setting, an individual's socially mediated beliefs about the opportunities each has to learn and the extent to which the social and physical milieu constrains learning." Researchers of learning environments argue the effects of traditional and nontraditional environments. Feng and Tuan (2005) applied the ARCS (Attention, Relevance, Confidence, and Satisfaction) model for acid and bases units. They compared the results with 
Güner Tural, Promoting Students' Understanding of the Concept of Pressure: Active Learning...

a traditional model to assess the motivation and achievement outcomes of 11 th graders. The research found that the ARCS model for teaching acids and bases unit improved the motivation and achievement of low motivated students more significantly than the traditional model. McCarthy and Anderson (2000) compared active learning and traditional teaching methods for history and science classes. The experimental group engaged in role-playing and collaborative activities, while the control group used teacher-centered discussions and lectures. The results showed that the active learning class students did better on subsequent standard evaluations than students in the traditional class. Park and Choi (2014) compared active learning and traditional classrooms at SoongSil University in Korea. They reported that an active learning environment increased student interaction, direct feedback in the learning process, class participation, interest in subject matter, students' willingness to ask questions in class, and communication with instructors. In the study of Yager et al. (2009), the Science-Technology-Society approach and traditional textbook approach were used to teach basic science concepts for two groups of teachers from five school districts. The Science-Technology-Society approach was significantly better than the traditional textbook approach on the process skills, application of concepts, creativity skills, nature of the scientific enterprise, processes in new situations, and more positive student attitudes about school science. The conclusion drawn was that the Science-Technology-Society approach is wellsuited to elementary schools. Finally, Lord (1997) investigated the effects of the traditional teacher-centered lecture and $5 \mathrm{E}$ model on undergraduate nonmajors in introductory biology. According to exam results, students in the $5 \mathrm{E}$ model scored significantly higher than students in the control group. Students in the course taught with the $5 \mathrm{E}$ model enjoyed the course more and understood the material better than $t$ in other science courses.

Traditional and nontraditional students' perceptions of teaching effectiveness were also researched. For example, Keller and Mattie (1991) compared traditional and nontraditional undergraduate students' perceptions of effective teaching behaviors. The report shows that nontraditional undergraduate students thought personality and interaction behaviors indicate effective teaching, while traditional students thought that behaviors would enhance grades. Limniou et al. (2018) investigated 200 students' views on traditional and flipped classroom teaching approaches. They concluded that the flipped classroom teaching approach provides an opportunity to develop higher-order thinking skills than the traditional teaching approach.

In summary, the above studies comparing traditional and nontraditional learning environments for many disciplines such as physics, history, biology, and chemistry reveal that the nontraditional learning environment is more effective in promoting better academic achievement, attitude, creativity, motivation, and process skills, reasoning, and conceptual 
understanding. Similarly, this study also compares traditional and active learning environments for learning the concept of pressure.

\section{Teaching and Learning Challenges of Pressure Topic}

The pressure concept is one of the science concepts that the students have difficulty to understand and construct. Many factors may affect the efficacy of teaching or learning the concept of pressure. One of the factors is students' preconceptions grounded in everyday experiences. Students often do not construct a scientifically correct description of the concepts; thus, misconceptions may arise from their intuitive concepts. The abstract nature of the pressure concept and especially invisibility for gases may cause difficulty in understanding. She (2005) states that the air pressure concept is an intricate science concept since it requires an understanding of invisible, abstract, and process attributes. She further explains that real event visualization help makes air pressure visible and concrete; thus, students can personally perceive the dynamic process. Furthermore, Kariotoglou and Psillos (1993) studied students' (13-14 years) pressure models in liquids and found that students' incorrect pressure models appeared after traditional instruction. They suggest teachers use particular learning strategies to teach pressure in liquids to make lessons more meaningful.

Kuethe (1991) suggests three misconceptions about pressure. The first misconception is that pressure is a measure of energy per unit volume. Students may equate 1 Pa with $1 \mathrm{~J} / \mathrm{m}^{3}$ and incorrectly calculate that the pressure of $1 \mathrm{~m}^{3}$ of water drops $1 \mathrm{~Pa}, 1 \mathrm{~J}$ of energy would be released. The second misconception is that fluids flow only from high to low pressure. The researcher state that students sometimes conclude the energy content of fluid flowing steadily through a horizontal pipe of constant diameter decreases because the pressure drops in the direction of flow (Kuethe 1991, p. 20). There is an incorrect electric current analogy that "electric charge flows from high voltage to low as fluids flow from high pressure to low," relating this topic. The third misconception is that pressure can be no lower than that of a vacuum. Tytler (1998) collected children's explanations about air and air pressure in different situations as well as ages and found that children's conceptions were complex.

The studies above reveal that students have difficulty understanding pressure, but generally, they focus only on one subtopic (gas pressure, pressure in liquids, or pressure in solids). Thus, this research aims to fill this gap and contribute to the literature by including all pressure subtopics.

\section{METHOD}

This study used the pre-test post-test quasi-experimental research design with a control group. In educational research, random assignation of participants to control or experimental groups is generally impossible (Cohen et al., 2011). Thus, educational researchers prefer the quasi-experimental method (Cohen et al., 2011; Kerlinger 1970) to determine cause-effect 
Güner Tural, Promoting Students' Understanding of the Concept of Pressure: Active Learning...

relationships between the variables (Fraenkel et al. 2012). In this study, one class was assigned as the control group, and the other as the experimental group. The study gave treatment to the class, and students' understanding was measured quantitatively.

\section{Participants}

The participants consisted of 30 students aged 13 to 14 years from a public secondary school in Turkey. Twelve of them were male, and eighteen of them were female. There were two classes for this grade: the control group consisted of 14 students, and the experimental group consisted of 16 students.

\section{Data Collection Tools}

The questionnaire included sixteen open-ended questions to reveal students' understanding of pressure. Questions in the questionnaire included an event or a situation related to gas pressure, pressure in liquids, or pressure in solids to ensure students can apply concepts and knowledge holistically. Some of the questions from the questionnaire were presented in the Appendix. Then structured interviews were conducted to collect opinions about the treatment in the experimental group. The data collection tools were applied to students in their classroom.

\section{Data Analysis}

The data were analyzed based on document analysis. A detailed rubric (Table 1), similar to a rubric developed by Abraham, Williamson, and Westbrook (1994), was used to evaluate the answers.

Table 1. The Rubric used for Evaluation of the Answers

\begin{tabular}{lcc}
\hline Categories & Shortenings & Scores \\
\hline $\begin{array}{l}\text { Correct Answer: Responses containing all components of } \\
\text { the scientifically accepted response }\end{array}$ & CA & 3 \\
$\begin{array}{l}\text { Partially Correct Answer: Responses that included at least } \\
\text { one of the components of validated response, but not all } \\
\text { the components }\end{array}$ & PC & 2 \\
$\begin{array}{l}\text { Correct-Wrong Answer: Responses that included both } \\
\text { scientifically correct and incorrect information }\end{array}$ & CW \\
$\begin{array}{l}\text { Wrong Answer: Responses containing scientifically incorrect } \\
\text { information }\end{array}$ & WA \\
No Answer: Blank & NA & 0 \\
\hline
\end{tabular}

The maximum score for the questionnaire is 48 . SPSS 17.0 program was used to analyze the quantitative data. Scale scores in this study were within the interval scale. Measures of 
Central Tendency, Histogram, Normal Q-Q Plot, and Shapiro-Wilk Test were performed. The statistical measurement shows that the data were normally distributed. Levene's Test also showed that group variances were equal. Necessary assumptions for the parametric test were provided; thus, an independent-samples T-test was employed. The interview notes were subjected to descriptive analysis, and excerpts from students' answers were presented to reflect students' opinions.

\section{Validity and Reliability}

One physics instructor from the university, one science teacher, and one postgraduate student examined the questionnaire to determine content validity. They reached a consensus on the questions and created an answer key to ensure data reliability. Additionally, an external researcher coded the questionnaire. Agreement percentage ( $P=$ /Consensus ( $\mathrm{Na}$ ) / Consensus ( $\mathrm{Na}$ ) + Dissidence (Nd)) X 100) that introduced by Miles and Huberman (1994) was 98, indicating that the results were accepted as reliable. Control group students were coded as $\mathrm{SC} 1, \mathrm{SC} 2, \ldots$ Experimental group students were coded as $\mathrm{SE} 1, \mathrm{SE} 2, \ldots$

\section{Procedure}

One week before the formal teaching, the control and experimental groups were given the pre-test. Before the application, the science teacher was given guidance on conducting the instructional design in the experimental group. The following phases were instructed for the study.

1. Firstly, the students' answers were examined, and students' prior knowledge about pressure was assessed via pre-test.

2. Secondly, a lesson was designed to enhance students' learning. In the teaching process, the existing science program was given to both groups. According to the Turkey National Science Curriculum, pressure should be divided into 40 minutes $x 10$ lessons.

3. The lessons were conducted based on the routines and schedule in their natural classroom setting. The same teacher-led the lessons for both classes to control the effect of the treatment.

4. In the control group, the teacher did the coursebook activities (Table 2), which used a demonstration method. In this group, the students were passive listeners in the learning process.

5. In the experimental group, additional activities and models (Figures 1-2, Table 3) were used differently from the control group. In this group, students performed the activities requiring interaction with the class. They studied in groups of two to three and were asked to collaborate and share knowledge. The groups had worksheets designed according to POE (predict, observe, explain) strategy. All the hands-on activities and models were low-cost. In the predict step, the teacher asked students to justify their prediction of the outcome of events or situations presented to them. For example, teachers showed a video about burning 
Güner Tural, Promoting Students' Understanding of the Concept of Pressure: Active Learning...

a candle on a dish filled with water and covering the candle with an inverted glass without showing the events' result. Teachers then asked: "Please predict what will happen and explain the reason(s) for your prediction?". Students may also read the event or the situation written on worksheets and then write their predictions on the same worksheets. In the observe step, students performed related activities and described what they observed. Finally, in the observe step, they compared the observation with their prediction. When the experimental group practiced the activities, a simple discussion was conducted via questions under the teacher's guidance. The students read, wrote, discussed, explained, and engaged in activities as active learning required.

6. Lastly, after the treatment, the same questionnaire was applied as a post-test. Opinions of experimental group students about the treatment were also asked in the semi-structured interviews.

The application of the research took ten lessons. Each lesson lasted for forty minutes.

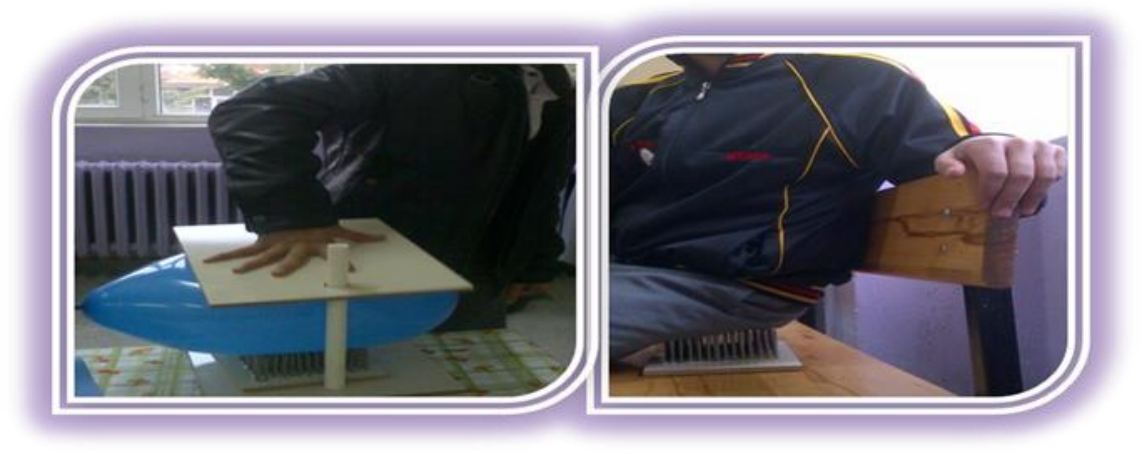

Figure. 1. Activities with a Studded Board Model

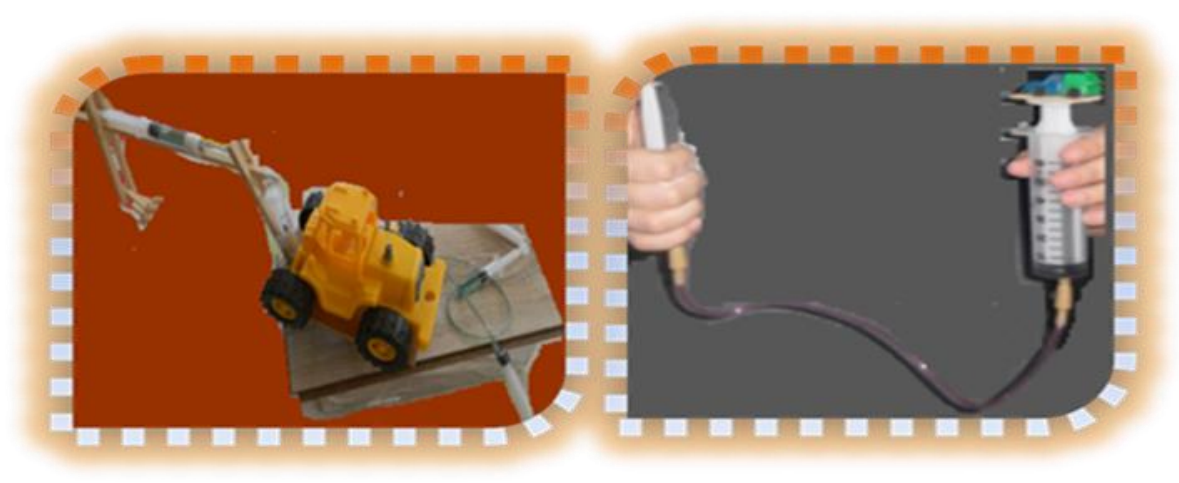

Figure. 2. Dipper Dredger and Hydraulic System Models 
Table 2. Hands-on Activities in the Course Book

\begin{tabular}{l}
\hline Activities \\
\hline Pressure in solids \\
Placing the brick horizontally and vertically on the sand \\
Pressure in liquids \\
Inked water is placed in the manometer. The funnel passed into the end of the \\
rubber hose is immersed in water and olive oil. The change in liquid level in the \\
manometer is observed.
\end{tabular}

Table 3. Additional Hands-on Activities and Models for Experimental Group

\begin{tabular}{ll}
\hline Activities & Models \\
\hline Pressure in liquids & Dipper dredger \\
The balloon is filled with water and pierced through different parts & Hydraulic system \\
The bottle is filled with water and drilled at different heights & \\
Gas pressure & \\
Closing the nozzle of the injected injector with a finger. Pushing and \\
releasing the piston of the injector \\
Balloon inflation with injector \\
Burning sparkling cotton in a tin \\
Water rising in the glass \\
Water not falling through the pipette \\
Pressure in solids \\
Leaving two identical books horizontally and vertically on a sponge \\
Blasting the balloon with the nail and third one is sitting on the studded \\
board
\end{tabular}

\section{RESULTS}

\section{Results from Questionnaire}

The independent samples T-test was conducted for experimental and control groups to compare students' prior knowledge of the "pressure" topic 
Güner Tural, Promoting Students' Understanding of the Concept of Pressure: Active Learning...

Table 4. T-Test Results According to Experimental and Control Groups of Pre-Test Scores

\begin{tabular}{lllllll}
\hline Groups & $\mathrm{N}$ & $\bar{x}$ & $\mathrm{~S}$ & $\mathrm{Df}$ & $\dagger$ & $\mathrm{P}$ \\
\hline Experimental & 16 & 7.94 & 2.11 & 28 & -1.926 & 0.064 \\
Control & 14 & 6.29 & 2.58 & & & \\
\hline
\end{tabular}

Table 4. shows that the mean scores of the control and experimental groups were 6.29 and 7.94, respectively. According to the t-test result, there was no statistically significant difference between the pre-test mean scores of students from the experimental group and those from the control group $(t(28)=-1.926, p>0.05)$.

After the implementation, the independent samples t-test was conducted to compare students' mean scores from the control and experimental groups.

Table 5. T-Test Results According to Experimental and Control Groups of Post-Test Scores

\begin{tabular}{lllllll}
\hline Groups & $\mathrm{N}$ & $\bar{x}$ & $\mathrm{~S}$ & $\mathrm{df}$ & $\mathrm{T}$ & $\mathrm{P}$ \\
\hline Experimental & 16 & 33.44 & 5.37 & 28 & -5.782 & 0.000 \\
Control & 14 & 18.79 & 8.37 & & & \\
\hline
\end{tabular}

Table 5 shows that the control and experimental groups' mean scores were 18.79 and 33.44 , respectively. There was a statistically significant difference between the post-test mean scores of students from the experimental group and those from the control group $(t(28)=-$ $5.782, p<0.05)$.

In addition to the data above, misunderstandings that emerged from both groups of students are shown below.

Table 6. Students' Specific Misunderstandings in Pre-Test and Post-Test

\begin{tabular}{lllll}
\hline Specific misunderstandings & Pre & Post & pre & post \\
\hline $\begin{array}{l}\text { MU1.Since there is no gravity in the } \\
\text { atmosphere, we do not feel the }\end{array}$ & & SC10 & & \\
$\begin{array}{l}\text { atmospheric pressure acting on us } \\
\text { MU2.We do not feel the atmospheric }\end{array}$ & SC5,SC6, & SC2,SC6, & SE3,SE7 & \\
$\begin{array}{l}\text { pressure acting on us due to gravity } \\
\text { SC11, SC12 }\end{array}$ & SC12 & \\
$\begin{array}{l}\text { MU3.Since the atmosphere is in the } \\
\text { sky, we do not feel the atmospheric }\end{array}$ & & & & \\
$\begin{array}{l}\text { pressure acting on us } \\
\text { MU4.A duck and a chicken with the }\end{array}$ & SC12 & SC6 & \\
\hline
\end{tabular}


same weight moving on snow, apply

equal pressure to the ground

because their weight is the same

MU5.The volume shrinks while a

$\mathrm{SC} 12$

SEI,SE11

released inflated balloon rises

MU6.Air pressure increases as we go

SC4,SC8,

SE3,SE13,

SE10

Higher

SC10

SE16

MU7.The volume increases while an

SC4

inflated balloon rises. Because air

pressure increases

MU8.The volume does not change

SC2,SC6

SE3,SE15

while a released inflated balloon

rises

MU9.The pressure acting on the

surface of a swimmer is higher than

that of sea bottom

MU10.We do not feel the

atmospheric pressure acting on us

since pressure of our body is bigger

than the pressure of the external

pressure

MUI 1.The air pressure is higher

because the atmosphere is more

above

MU12.The volume shrinks while an

inflated balloon rises. Because the

outside pressure is higher

MU13.We do not feel the

atmospheric pressure because of

our weight

MU14.A duck and a chicken with

the same weight moving on snow,

the duck applies more pressure to

the snow

MU15.We do not feel the

atmospheric pressure acting on us

because the atmospheric pressure is

small from our pressure 
Güner Tural, Promoting Students' Understanding of the Concept of Pressure: Active Learning...

MU16.A duck and a chicken with

the same weight moving on snow,

the surface area of chicken is

smaller. The duck applies more

pressure to the snow

MU: Misunderstanding

Table 6 shows that students from the control and experimental group had misunderstandings in all subtopics (pressure in solids, pressure in liquids, gas pressure) of the pressure topic. The misunderstandings emerged after implementation. The misconceptions were MU5, MU6, MU7, MU8, MU9, and MU10 from the control group and MU14 and MU16 from the experimental group.

\section{Results from Interview}

The opinions of participants from the experimental group about the class were presented in the following.

Q1. Please explain the effects of the current teaching sequence of pressure topic in terms of comprehending the subject.

About the effects of the current teaching sequence of pressure topic, twelve of the students stated that the treatment created better learning, and two said easier understanding. However, two students said that the application did not have any effects. The excerpts from the students' opinions are as follows:

The activities were fun. They motivated me. On this count, I learned the subject better (SE1).

The activities did not affect my learning but I was interested in some parts (SE3).

The application was enjoyable. It took my attention to the subject. So I learned the subject easier. The information was memorable. I can solve test questions about this subject more easily (SE7).

The activities provided questioning via how and why questions. Thus this application helped better understanding (SE11).

Q2. Did the current teaching sequence of pressure topic affect your interest to science lesson?

After the teaching sequences, fourteen students said that their interest in science lessons increased. One student stated a little interest, and another one said no interest increase to the science lesson. The excerpts from the students' opinions are as follows: 
The application was very fun. I started to show more interest in the course (SE2).

It was a lot of fun and enjoyable compared to our previous science lessons.

This increased my desire for learning against science (SE6).

I have not had much interest in science before. These activities and materials interested me. It raised my curiosity. So my interest increased in science course (SE12).

This application created a little interest and love for science course. It's a lot of fun to do lesson so (SE13).

Q3. How did the current teaching sequence of pressure topic you used in the classroom contribute you to associate the subject with daily life?

All the students stated that such a teaching sequence helped them associate the pressure topic with daily life. The excerpts from the students' opinions are as follows:

This application had a positive contribution to associate daily life events. Now I know why mom holes to oil tin can from two sides. I can explain where is easier for swimming. The surface or the bottom of the sea. Also I can say the reason of it. Now I can understand why our noses bleed when we go the heights (SE1).

When I wear thin heels and thick heel shoes, I can relate the difference in walking to pressure (SE2).

I can understand why large pallets are preferred in some of the work machines. I can explain divers' risk of contracting the bends (SE5).

I can now understand how water can get to our homes in our daily lives, how airbags work in cars and why oil tin cans pierce from both sides (SE7).

\section{DISCUSSION}

The present study investigated the effectiveness of an active-learning environment in terms of the students' understanding of the concept of pressure. Before instruction, a pre-test was administered to students in the control and experimental groups to identify their prior knowledge of pressure. In the control group, the teacher explained the content, gave examples, elaborated on the topic of pressure, and explained the course book's activities. The students were only passive listeners in the learning process. In the experimental group, the teacher was a guide supporting the students' learning. The students in the experimental group performed group work via worksheets designed according to POE. In addition to activities in the coursebook, they did many hands-on activities. They also carried out some activities via models (Table 3) prepared for the topic. They exchanged ideas with each other 
Güner Tural, Promoting Students' Understanding of the Concept of Pressure: Active Learning...

in each group. When the activities were being held, the teacher provided questions to help them think about and investigate the topic.

We can see research on different science topics in the literature (Acar Sesen and Tarhan 2011; Burrowes 2003; Chiu and Cheng 2017; Kim et al. 2013; Marbach-Ad and Sokolove 2002; Taraban et al. 2007; Towns and Grant 1997) that showed the positive impact of an active learning environment on student learning. Many studies investigate students' pressure concepts, but studies that comparatively examine the effect of learning environments to learn this topic, such as present work, are quite limited.

This study demonstrated that an active learning environment in which the students have an active role in their learning was more effective in teaching pressure. This finding is in line with Kariotoglou and Psillos (2019), which conducted research with a similar procedure, but different in terms of topic, as Kariotoglou and Psillos (2019) examined only pressure in liquids.

Although pressure is present in everyday life, students rarely used this concept in the answers they gave before instruction. This concept was used in the responses after instruction, but misunderstandings emerged, which were not present before the lesson (Table 6). These misunderstandings were six for the control group and two for the experimental group. In the control group, students had four and nine misunderstandings before and after instruction, respectively. Based on the research results, some misunderstandings were more frequently expressed by students than the others. The first one was, "We do not feel atmospheric pressure acting on us due to gravity." Prescott \& Mitchelmore (2009) state that misunderstandings about gravity's nature are common, and one of them is that gravity is the result of air pressure. The present study shows that the students established a relationship between gravity and atmospheric pressure. Students' opinion of the relationship between these two concepts is also seen in their first misunderstanding, which was, "Since there is no gravity in the atmosphere, we do not feel the atmospheric pressure acting on us." The second misunderstanding, which was more often expressed by students, was, "Air pressure increases as we go higher." Michael's (1998) research on undergraduate students' misunderstandings about perceived physiological responses showed that a substantial number of students think that air pressure increases at the top of the mountain. Abstract concepts such as gases and air cannot be seen. Hence, the misunderstandings may be caused by the abstract structure of air.

Furthermore, some research (Chi et al. 1994; She 2002) states that students have difficulty understanding invisible and abstract science concepts. Thus, designing suitable learning environments to concrete these abstract concepts is essential. The coursebook used in this research does not include any activities to learn gas pressures (Table 2). In contrast, the experimental group students performed five activities related to gas pressure (Table 3). 
Interestingly, before instruction, six students from the control group had misunderstandings about gas pressure, and after instruction, the number increased to seven students. Only the student coded as SC5 did not have any misunderstanding related to gas pressure after instruction. Also, two of them (SC4 and SC8) emerged after instruction. This situation may be because of inadequate learning and not unorganized explanation of the concept. Besides, students in this traditional group may not be able to connect what they are learning and how that knowledge will be used.

Before instruction, six students from the experimental group had misunderstandings about gas pressure, and after instruction, only SE10 had the misunderstanding.

The finding that students have positive opinions about such a teaching sequence is in line with studies of Armbruster et al. (2009), Owen et al. (2008), Tural (2015), Tural and Tarakç। (2017) in the literature that shows students' positive opinions or attitudes about an active learning environment.

\section{CONCLUSION}

Before the instruction, the pre-test results showed no statistical differences between the groups. After the instruction, the post-test results showed a significant difference in favor of the experimental group. Thus, this research concludes that an active learning environment in which the students have an active role in their learning was more effective in teaching the topic of pressure.

Misunderstandings on this topic were found in both groups. The total number of misunderstandings was sixteen and included all the pressure subtopics. Before instruction, the control group students had four misunderstandings. The number increased to nine after the instruction was given. In contrast, the experimental group students had nine misunderstandings before the instruction, but only three after the instruction. In other words, the misunderstandings decreased in the experimental group. Hence, the research shows that an active learning environment reduces misunderstandings for this study group.

The interviews showed that students in the experimental group perceived an active learning environment ensured better and easier learning. Most of the students said that their interest in the science lesson increased after the teaching sequence. All of these students also stated that the active learning environment that was designed for them helped them associate the topic of pressure with daily life. Thus, it can be concluded that students have positive opinions about such a teaching sequence.

The present research results are limited to the present study group; thus, generalization to a population cannot be made, as significant effects may only apply to subjects in this research scope. The present study contributes to the literature by researching one of the subtopics of 
Güner Tural, Promoting Students' Understanding of the Concept of Pressure: Active Learning...

pressure topics and examining them in one study using quantitative and qualitative measures. Also, the construction and evaluation of the questionnaire are quite detailed. These are the strengths of the study. Since this research was designed for middle school students, further research is recommended to carry out a cross-sectional study to expand the scope. The present study's positive results also encourage research for other science topics in a similar teaching sequence.

\section{ACKNOWLEDGMENTS}

Thank you to the teacher Uğur Akdin for applying this teaching sequence in the classroom.

\section{APPENDIX}

\section{Some of the questions from the questionnaire}

Q1. Which principle does provide to move the bucket of the dipper dridger?

Q2. In 1664, Otto Von Guerrike conducted an experiment called the Magdeburg Half-Spheres. Two large hemispheres with metal are joined together and the air is discharged. Then, several horses are tried to separate the half-spheres from each other but the spheres are not separated. What is the effect that provides it? Please explain.

Q3. What is the principle that allows water to flow higher?
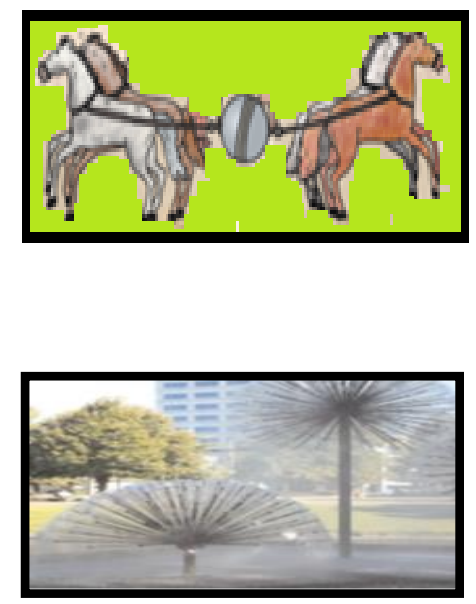

Q4. Why after flying to a certain height in the hot air balloon, Jane's nose starts bleeding?

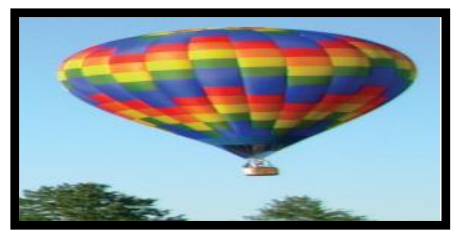

\section{REFERENCES}

Armbruster, P., Patel, M., Johnson, E., \& Weiss, M. (2009). Active learning and studentcentered pedagogy improve student attitudes and performance in introductory biology. CBE-Life Sciences Education, 8(3), 203-213. doi: 10.1187/cbe.09-03-0025

Besson, U. (2010). Calculating and understanding: formal models and causal explanations in science, common reasoning and physics teaching. Science \& Education, 19, 225-257. doi: $\underline{10.1007 / s 11191-009-9203-9}$ 
Besson, U., \& Viennot, L. (2004). Using models at the mesoscopic scale in teaching physics: two experimental interventions in solid friction and fluid statics. International Journal of Science Education, 26(9), 1083-1110. doi: 10.1080/0950069042000205396

Bonwell, C. C., \& Eison, J. A. (1991). Active learning: creating excitement in the classroom. ASHE-ERIC Higher Education Report No.1. Washington, D.C.: The George Washington University, School of Education and Human Development.

Burrowes, P. A. (2003). A student-centered approach to teaching general biology that really works: lord's constructivist model put to a test. American Biology Teacher, 65(7), 491-494. doi: 10.1662/0002-7685(2003)065[0491:ASATTG]2.0.CO;2

Chi, M. T. H., Slotta, J. D., \& Deleeuw, N. (1994). From things to processes: a theory of conceptual change for learning science concepts. Learning and Instruction, 4, 27-43. doi: $10.1016 / 0959-4752(94) 90017-5$

Chiu, P. H. P., \& Cheng, S. H. (2017). Effects of active learning classrooms on student learning: a two-year empirical investigation on student perceptions and academic performance. Higher Education Research \& Development, 36(2), 269-279. doi: $\underline{10.1080 / 07294360.2016 .1196475}$

Cohen, L., Manion, L., \& Morrison, K. (2011). Research Methods in Education. Routledge: New York.

Engel Clough, E., \& Driver, R. (1985). What do children understand about pressure in fluids? Research in Science and Technological Education, 3, 133-144. doi: $10.1080 / 0263514850030106 a$

Faulconer, E. K., Griffith, J., Wood, B., Acharrya, S., \& Roberts, D. (2018). A comparison of online, video synchronous, and traditional learning modes for an introductory undergraduate physics course. Journal of Science Education and Technology, 27(5), 404-411. doi: $10.1007 /$ s 10956-018-9732-6

Feng, S. L., \& Tua, H. L. (2005). Using ARCS model to promote 11 th graders' motivation an achievement in learning about acids and bases. International Journal of Science and Mathematics Education, 3, 463-484. doi: 10.1007/s10763-004-6828-7

Fernandez, F. B. (2017). Action research in the physics classroom: the impact of authentic, inquiry based learning or instruction on the learning of thermal physics. Asia-Pacific Science Education, 3(3), 1-20. doi:10.1186/s41029-017-0014-z

Fraenkel, J. R., Wallen, N. E. \& Hyun, H. H. (2012). How to Design and Evaluate Research in Education. New York: McGraw-Hill.

Julia, C., \& Antoli, J. O. (2018). Impact of implementing a long-term stem-based active learning course on students' motivation. International Journal of Technology and Design Education, 1-25. doi: $10.1007 /$ s 10798-018-9441-8

Kariotoglou, P., \& Psillos, D. (1993). Pupils' pressure models and their implications for instruction. Research in Science \& Technological Education, 11(1), 95-108. doi: $10.1080 / 0263514930110109$

Kariotoglou, P., \& Psillos, D. (2019). Teaching and learning pressure and fluids. Fluids, 4(4), 194204. doi: 10.3390/fluids 4040194

Keller, J. W., \& Mattie, N. (1991). Teaching effectiveness: comparisons between traditional and nontraditional college students. Innovative Higher Education, 15(2), 177-183. doi: 10.1007/BF00898029 
Güner Tural, Promoting Students' Understanding of the Concept of Pressure: Active Learning...

Kerlinger, F. N. (1970). Foundations of Behavioral Research. Holt, Rinehart and Winston, New York.

Killian, M., \& Bastas, H. (2015). The effects of an active learning strategy on students' attitudes and students' performances in introductory sociology classes. Journal of the Scholarship of Teaching and Learning, 15(3), 53-67. doi: 10.14434/josotl.v15i3.12960

Kim, J. S. (2005). The effects of a constructivist teaching approach on student academic achievement, self-concept, and learning strategies. Asia Pacific Education Review, 6(1), 7-19. doi: 10.1007/BF03024963

Kim, K., Sharma, P., Land, S. M., \& Furlong, K. P. (2013). Effects of active learning on enhancing student critical thinking in an undergraduate general science course. Innovative High Education, 38, 223-235. doi: 10.1007/s10755-012-9236-x

Kuethe, O. D. (1991). Confusion about pressure. The Physics Teacher, 29(1), 20-22. doi: $10.1119 / 1.2343194$

Kuvac, M., \& Koc, I. (2018). The effect of problem-based learning on the environmental attitudes of preservice science teachers. Educational Studies, 1-23. doi: 10.1080/03055698.2018.1443795

Limniou, M., \& Schermbrucker, I., \& Lyons, M. (2018). Traditional and flipped classroom approaches delivered by two different teachers: the student perspective. Education and Information Technologies, 23, 797-817. doi: 10.1007/s10639-017-9636-8

Lord, T. R. (1997). A comparison between traditional and constructivist teaching in college biology. Innovative Higher Education, 21 (3), 197-216. doi: 10.1007/BF01243716

Lorsbach, A., \& Tobin, K. (1995). Toward a critical approach to the study of learning environments in science classrooms. Research in Science Education, 25(1), 19-32. doi: $10.1007 / \mathrm{BF} 02356457$

Marbach-Ad, G., \& Sokolove, P. G. (2002). The use of e-mail and in-class writing to facilitate student-instructor interaction in large-enrollment traditional and active learning classes. Journal of Science Education and Technology, 11(2), 109-119. doi: 10.1023/A:1014609328479

McCarthy, J. P., \& Anderson, L. (2000). Active learning techniques versus traditional teaching styles: two experiments from history and political science. Innovative Higher Education, 24(4), 279-294. doi: 10.1023/B:IHIE.0000047415.48495.05

Michael, J. A. (1998). Students' misconceptions about perceived physiological responses. Advances in Physiology Education, 274(6), 90-98. doi: 10.1152/advances.1998.274.6.590.

Miles, M. B., \& Huberman, A. M.. (1994). Qualitative Data Analysis. London: Sage Publications.

Morosan, C., M. Dawson, \& Whalen, E. A. (2017). Using active learning activities to increase student outcomes in an information technology course. Journal of Hospitality \& Tourism Education, 29(4), 147-157. doi: 10.1080/10963758.2017.1382369

Niemi, H., Nevgi, A., \& Aksit, F. (2016). Active learning promoting student teachers' professional competences in Finland and Turkey. European Journal of Teacher Education, 39(4), 471-490. doi: 10.1080/02619768.2016.1212835

Owen, S., Dickson, D., Stanisstreet, M., \& Boyes, E. (2008). Teaching physics: students' attitudes towards different learning activities. Research in Science \& Technological Education, 26(2), 113-128. doi: 10.1080/02635140802036734 
Park, E. L., \& Choi, B. K. (2014). Transformation of classroom spaces: traditional versus active learning classroom in colleges. Higher Education, 68, 749-771. doi: 10.1007/s10734-014$9742-0$

Prescott, A., \& Mitchelmore, M. (2009). The impact of teacher misconceptions about projectile motion on student learning. Cosmed Proceedings International Conference on Science and Mathematics Education, 46-53.

Psillos, D., \& Kariotoglou, P. (1999). Teaching fluids: intended knowledge and students' actual conceptual evolution. International Journal of Science Education, 21(1), 17-38. doi: $10.1080 / 095006999290813$

Sere, M. G. (1982). A study of some frameworks used by pupils aged 11 to 13 years in the interpretation of air pressure. International Journal of Science Education, 4(3), $299-309$. doi: 10.1080/0140528820040309

Sesen, B. A., \& Tarhan, L. (2011). Active-learning versus teachercentered instruction for learning acids and bases. Research in Science \& Technological Education, 29(2), 205226. doi: $10.1080 / 02635143.2011 .581630$

She, H. C. (2002). Concepts of higher hierarchical level required more dual situational learningevents for conceptual change: a study of students' conceptual changes on air pressure and buoyancy. International Journal of Science Education, 24(9), 981-996. doi: 10.1080/09500690110098895

She, H. C. (2005). Promoting students' learning of air pressure concepts: the interrelationship of teaching approaches and student learning characteristics. The Journal of Experimental Education, 74(1), 29- 51. doi: 10.3200/JEXE.74.1.29-52

Şahin, Ç., Akbulut, H. I.., \& Çepni, S. (2012). Teaching of solid pressure with animation, analogy and worksheet to primary 8th students. The Journal of Instructional Technologies \& Teacher Education, 1 (1), 22-51.

Taraban, R., Box, C., Myers, R., Pollard, R., \& Bowen, C. W. (2007). Effects of active-learning experiences on achievement, attitudes and behaviours in high school biology. Journal of Research in Science, 44(7), 960-979. doi: 10.1002/tea.20183

Taylor, N., \& Lucas, K. B. (2000). Implementing and evaluating a sequence of instruction on gaseous pressure with preservice primary school student teachers. Australian Science Teachers Journal, 46(4), 9-34.

Towns, M. H., \& Grant, E. R. (1997). I believe I will go out of this class actually knowing something: cooperative learning activities in physical chemistry. Research in Science Teaching, 34(8), 819-835. doi: 10.1002/(SICI) 1098-2736(199710)34:8<819::AIDTEA5>3.0.CO;2-Y

Tural, G. (2015). Active learning environment with lenses in geometric optics. Asia-Pacific Forum on Science Learning and Teaching, 16(1), 1-18.

Tural, G., \& Tarakçı, D. (2017). Effects of physical models and simulations to understand daily life applications of electromagnetic induction. Research in Science \& Technological Education, 35(3), 292-307. doi: 10.1080/02635143.2017.1295370

Tytler, R. (1992). Children's explanations of air pressure generated by small group activities. Research in Science Education, 22(1), 393-402. doi: 10.1007/BF02356920

Tytler, R. (1998). Children's' conceptions of air pressure: exploring the nature of conceptual change. International Journal of Science Education, 20(8), 929-958. doi: $10.1080 / 0950069980200803$ 
Güner Tural, Promoting Students' Understanding of the Concept of Pressure: Active Learning...

Yager, R. E., Choi, A., Yager, S. O., \& Akcay, H. (2009). Comparing science learning among 4th-, 5th-, and 6th- grade students: STS versus textbook-based instruction. Journal of Elementary Science Education, 21 (2), 15-24. doi: 10.1007/BF03173681 